\title{
Impact of Automation to Maritime Technology
}

\author{
Song Ding, Duanfeng Han, Boshi Zhang \\ College of Shipbuilding Engineering, Harbin Engineering University \\ Harbin, 150001, China \\ E-mail: dingsongsm@126.com
}

\begin{abstract}
Due to incredibly advancing technology and reduced manning levels in the maritime industry there is now a cultural shift in the maritime industry toward increased levels of automation in tasks, particularly with regard to navigation systems. But there are two sides to the automation advances. Increasing automation causes the loss of situation awareness, which can significantly affect performance in abnormal, timecritical circumstances. This paper presents an overview of the application of automation in marine system and its impact to the system's performance.
\end{abstract}

Keywords-automation; situation awareness; maritime;

\section{INTRODUCTION}

The current economics of maritime operations has led the industry towards minimal manning. Technological advances have also led to major changes in the role of human operators, many of which remove the operator from the systems control. Some of these advances include automatic data logging, position fixing aids, restricted navigation aids, collision avoidance systems cargo planning aids, automatic route following, and maintenance diagnostic aids. In some cases, these types of automation have reduced crew sizes from 30 to 40 crewmembers, to 15 to 21 [1]. Automation has turned many mariners into system managers, responsible for coordinating and monitoring multiple automatic systems.

The use of automation on ships has had impacts on the deck department and engineering. Advances have been made in radar and progressed to radar enhanced with automated radar plotting aids (ARPA). Recently, electronic chart display information systems (ECDIS) are being used. Many countries are working on developing fully integrated bridges. The idea is to use multiple automated systems to produce a massive integration of navigation and ship control systems, possibly requiring the use of only one mariner on the bridge to acts as helmsman, lookout, and watch officer. The idea that automation enhances safety and decreases human workload seems to be a reasonable assumption, but it is actually a debatable topic.

Since the systems to be monitored continue to increase in complexity with the addition of automation, an increased trend towards large catastrophic failures often accompanies the incorporation of automation [2] [3]. When things go wrong, they go wrong in a big way. In examining these failures, it becomes apparent that the coupling of human and machine in the form of observer and performer is far from perfect in terms of optimizing the overall functioning of the joint human-machine system.

\section{AutOMATION APPLiCATION}

A ship is unlike any form of transportation. In many cases, a ship is underway thousands of miles from shore. This requires that the ship and its crew be a self-sufficient entity, able to deal with any number of possible accidents and emergencies. Determining the size of crew for a particular ship is a tough engineering problem, mainly due to economic pressures. Using automation can reduce manning requirements but there is a point that the crew is just too small to remain alert, diligent, and able to safely operate the vessel.

The "old" system of engine room management generally consists of a wiper, water tender, an oiler, a fireman, and an engineer. Although the U.S. Coast Guard still uses this system, the merchant fleet desires to use minimal personnel in the engineering spaces. As of late, automation has enabled many engine rooms to go unmanned. The machinery and engine spaces are remotely monitored, allowing engineers to work there during the day and go "on call" during the night. This has significantly reduced costs in terms of manning but has greatly increased levels of stress among crew, especially captains. John Lee and Thomas Sanquist (1996) describe one ship's captain who said that having an unmanned engine room during voyages greatly increased his stress levels [4].

In the automation debate, two ideas about the benefit of automation were presented by Harold Blackman (1998) [5]. They are:

- Automation will reduce workloads.

- Automation will reduce human error.

These two benefits of automation are also areas that cause a number of problems for human operators.

A reduction in workload is beneficial to the human operator in term of task management but it trends to pull the operator "out of loop". Using automation to monitor system, such as in nuclear plant or industrial plants, eased the supervisory burden of such operators but can decrease the operator's understanding of the system status. In a high workload environment, operators can quickly lose control of a system if steps taken by automation are not readily displayed and understood. The automated system can quickly perform a number of tasks. This can leave the operator without a clear understanding of what happened in a systems transition or what is going to. 
The use of automation to decrease human error also contributes to the loss of an operator's system status awareness. Computer controlled systems perform thousands of complex algorithms per sound and their outcome may not always be apparent to the operator. The lack of understanding of the system status by the operator becomes a disadvantage in emergencies. When emergencies do occur, the operator may have little or no idea about what happened or where there was an error in the automation. The lack of information and understanding quickly puts the operator in a dangerous and sometimes hopeless situation.

Each of these problems can be directly linked to a low level of situation awareness that people operator as monitors of automated system. Situation Awareness, a people's mental model of the world around them, is central to effective decision making and control in dynamic system. This construct can be severely impacted by the implementation of automation.

\section{SITUATION AWARENESS}

Originally a term used in the aircraft pilot community, situation awareness has developed as a major concern in many other domains where people operate complex, dynamic systems, including nuclear power industry, automobiles, air traffic control and medical systems. Hartel, Smith and Prince (1991) found poor situation awareness to be the leading casual factor in military aviation mishaps [6]. In a recent review of commercial aviation accidents, 88 percent of those with human error involved a problem with situation awareness [7]. Situation awareness clearly is critical to performance in these environments.

Furthermore, Endsley (1996) expresses that Situation Awareness is equally important in maritime domain cause its complex and dynamic environments [8]. Wagenaar and Groeneweg (1987) state in their review of 100 shipping incidents that cognitive problems were responsible for $70 \%$ of observed human errors [9]. Grech, Horberry, and Smith (2002) examined human error in maritime operations from 177 maritime accident reports, accidents occurring between 1987 and 2000, from 8 countries. They observed that 71\% of all human error types on ships are situation awareness related problems [10].

Further, looking at the types and causes of those human errors reveals that failures of situation assessment and awareness are exceedingly common. Fig. 2 presents data related to the types of human errors reported in accident reports [11].

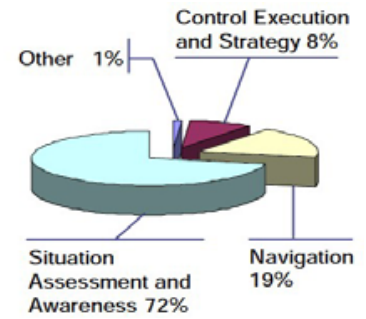

Figure 1. Types of Human Errors Reported (USCG Data)
Situation awareness is formally defined as "the perception of the elements in the environment within a volume of time and space, the comprehension of their meaning and the projection of their status in the near future" [12]. About Situation Awareness, Endsley has established its model, shown in Table1. These higher levels of situation awareness are critical for allowing decision makers to function in a timely and effective manner.

\section{TABLE I. ENDSLEY'S SA ERROR TAXONOMY}

Level 1: Failure to correctly perceive information such as:

$>$ Data not available

$>$ Data hard to discriminate or detect

$>$ Failure to monitor or observe data

$>$ Misperception of data

Level 2: Failure to correctly integrate or comprehend information such as:

$>\quad$ Lack of poor mental model

$>$ Use of incorrect model

$>$ Over reliance on default values

$>$ Memory loss

Level 3: Failure to project future actions or state of the system such as:

$>\quad$ Overprojection of current trends

For instance, in an aircraft environment, operators must aware of critical flight parameters, the states of their onbroad system, their own location and the location of important reference points and terrain, and the location of other aircraft along with relevant flight parameters and characteristics. This information forms the "elements" they need to perceive to have good Level $1 \mathrm{SA}$. But a great deal has to do with how the operators interpret the information they take in. They need to comprehend that a certain pattern of flight parameters indicates that they are near stall point, or that the displayed altitude is below their assigned altitude. This understanding forms their Level 2 SA. At the highest level, Level $3 \mathrm{SA}$, their understanding of the state of the system and its dynamics can allow them to be able to predict its state in the near future. A group of enemy aircraft flying in a particular formation will thus be projected to attack in a given manner. With accurate and complete situation awareness, operators can act to bring their system into conformance with their goals.

To the present day research on Situation Awareness has primarily been restricted to the aviation and recently to a certain extent to the medical domain (Endsley, 1996). However, a review of the literature clearly indicates that previously very little work has been carried out in the maritime domain on issue related to SA (Grech \&Horberry, 2002).

\section{IMPACT OF AUtimation ON SituAtion AwARENESS}

Automation can be seen to directly impact situation awareness through three major mechanisms (1) changes in vigilance and complacency associated with monitoring, (2) assumption of a passive role instead of an active role in controlling the system, and (3) changes in the quality or form of feedback provided to the human operator [13]. Each of 
these factors can contribute to the out-of-the-loop performance problem. In addition, automated systems, by nature of their complexity, also challenge the higher levels of situation awareness (comprehension and projection) during ongoing system operations.

\section{A. Vigilance, Complacency and Monitoring}

There is a long history of cases in which operators are reportedly unaware of automation failures and do not detect critical system state changes when acting as monitors of automated systems [14] [15] [16] [17]. Although monitoring failures have typically been associated with simple, lowevent tasks, Parasuraman (1987) concludes that "vigilance effects can be found in complex monitoring and that humans may be poor passive monitors of an automated system, irrespective of the complexity of events being monitored" [18]. There are many cases of problems in monitoring aircraft automation. Billings (1991) reports that the probability of human failure in monitoring automation increases when devices behave reasonably but incorrectly, and when operators are simply not alert to the state of automation [19].

Complacency, over-reliance on automation, is one major factor associated with a lack of vigilance in monitoring automation. Complacency has been attributed to the tendency of human operators to place too much trust in automated systems. ( Danaher, 1980; Parasuraman, Molloy, \& Singh, 1993; Wiener, 1985). Singh, Molloy and Parasuraman (1993) found that complacency was a function of a person's trust in, reliance on and confidence in automation [20] [21] [4] [22]. Trust in the automated system is a critical factor necessary for it to be employed by operators [23] [24]. Associated with this trust, however, operators may elect to neglect the automated system and the system parameters overseen by the automation in favor of other tasks through a shifting of attention [25], resulting in low situation awareness on these factors. The demands of other tasks in complex, multi-task environments have also been directly linked to complacency effects [26]. As an operator's attention is limited, this is an effective coping strategy for dealing with excess demands. The result, however, can be a lack of situation awareness on the state of the automated system and the system parameters it governs.

Monitoring problems have also been found with systems that have a high incidence of false alarms, leading to a lack of trust in the automation. Wiener and Curry (1980) and Billings (1991) report on numerous failures by aircrews to heed automatic alarms, leading to serious accidents [27]. Even though the system provides a noticeable visual or auditory signal, the alarms are ignored or disabled by flight crew who have no faith in the system due to its high false alarm rate.

Thus significant reductions in situation awareness can be found with automated systems, as people may (1) neglect to monitor the automation and its parameters, (2) attempt to monitor them, but fail due to vigilance problems, or (3) be aware of problems via system alerts, but not comprehend their significance due to high false alarm rates.

\section{B. Active vs. Passive}

In addition to vigilance problems, the fact that operators are passive observers of automation instead of active processors of information may add to their problems in detecting the need for manual intervention and in reorienting themselves to the state of the system in order to do so. Evidence suggests that the very act of becoming passive in the processing of information may be inferior to active processing [28] [29]. This factor could make a dynamic update of system information and integration of that information in active working memory more difficult.

In a recent study, Endsley and Kiris (1995) found that subjects' situation awareness was lower under fully automated and semi-automated conditions than under manual performance in an automobile navigation task. Only level 2 SA, understanding and comprehension, was negatively impacted, however; Level 1 SA was unaffected. Thus, although they were aware of low level data (effectively monitoring the system), they has less comprehension of what the data meant in relation to operational goals. The out-of-the-loop performance problem associated with automation was observed in the automated conditions.

This finding was specifically attributed to the fact that operators in the automated conditions were more passive in their decision making processes, drawing on the automated expert system's recommendations. Under the conditions of the experiment, there was no change in information displayed to the operators and vigilance and monitoring effects were insufficient to explain the situation awareness decrement. Turning a human operator from a performer into an observer can, in and of itself, negatively effect situation awareness, even if the operator is able to function as an effective monitor, and this can lead to significant problems in taking over during automation failure.

\section{Feedback}

A change in the type of system feedback or a complete loss of feedback has also been cited as a problem associated with automation [30]. "Without appropriate feedback people are indeed out-of-the-loop. They may not know if their requests have been received, if the actions are being performed properly, or if problems are occurring”. He attributes this problem largely to an erroneous belief by system designers that information on certain parameters is no longer needed by system operators once relevant functions are assumed by automation.

In some cases, critical cues may be eliminated with automation and replaced by other cues that do not provide for the same level of performance. In many systems, important cues may be received through auditory, tactile or the olfactory senses. When processes are automated, new forms of feedback are created, frequently incorporating more accurate visual displays; yet the fact that information is in a different format may make it harder to assimilate with other information or less salient in a complex environment. Young (1969) and Kessel and Wickens (1982) found that proprioceptive feedback received during manual control was important to performance and denied in automated tracking 
tasks in which information was only presented visually. The development of electronic fly-by-wire flight controls in the F-16 led to problems in determining airspeed and maintaining proper flight control, as the vibration information that usually came through the flight stick was suddenly missing (even though the needed information was clearly indicated on traditional visual displays) [31]. Artificial stick-shakers are now routinely added to fly-bywire systems to put back in the feedback that operators are accustomed to [32].

In some cases, the design of the automated system intentionally conceals information from the operator.Some autofeathering systems, for instance, have neglected to notify pilots of their actions in shutting down engines, leading to accidents. In some notable accidents, the fact that the automated system had failed was not clearly indicated to the operator, as in the Northwest Airlines accident in Detroit [33]. In addition, there is a tendency for some displays to eliminate raw system data, in favor of processed, integrated information. Important information as to the source of information, its reliability, or the value of constituent data underlying the integrated information may be unavailable. Billings (1991) notes that the clarity of the integrated displays may be seductive, yet highly misleading if such underlying information is not known.

A noted problem in many systems is the lack of information salience that may accompany automation. Frequently displays associated with complex automated systems involve computerized CRT screens with information imbedded in hierarchical displays that may be associated with various system modes. Problems with getting lost in menus, finding the desired display screen, and interpreting cluttered displays have been noted. The increased display complexity and computerized display format reduces the perceptual salience of information, even if it is available. In a complex environment with many activities going on, it is easy for operators to lose track of such information.

Either intentionally or inadvertently, the design of many systems posses a considerable challenge to situation awareness through the elimination of or change in the type of feedback provided to operators regarding the system's status. Unless very careful attention is paid to the format and content of information displays, these issues can easily sabotage situation awareness when operators are working with automated systems.

\section{Lack of Understanding of Automation}

One of the major impediments to the successful implementation of automation is the difficulty many operators have in understanding automated systems, even when they are attending to them and the automation is working as designed. This may be partially attributed to the inherent complexity associated with many of these systems, to poor interface design and to inadequate training.

The development and maintenance of situation awareness involves keeping up with a large quantity of rapidly changing system parameters, and then integrating them with others parameters, active goals and one's mental model of the system to understand what is happening and project what the system is going to do. This allows operators to behave proactively to optimize system performance and take actions to forestall possible future problems. As complexity increases (as it is apt to do with automation), this task becomes even more challenging. The number of parameters increases, and they change and interact according to complex underlying functions. Achieving an accurate mental model of the system can be very difficult, and this taxes the ability of the operator to attain the higher levels of situation awareness (comprehension and projection) from information that is perceived. By adding to system complexity, therefore, automated systems may make achieving good situation awareness more difficult.

Wiener (1989) has documented many problems with a lack of understanding of automated systems in aircraft by the pilots who fly with them [34]. McClumpha and James (1994) conducted an extensive study of nearly 1000 pilots from across varying nationalities and aircraft types [35]. They found that the primary factor explaining variance in pilots' attitudes towards advanced technology aircraft was their self-reported understanding of the system. While understanding tended to increase with number of hours in the aircraft, this also was related to a tendency to report that the quality and quantity of information provided was less appropriate and more excessive. Although pilots are eventually developing a better understanding of automated aircraft with experience, the systems do not appear to be well designed to meet their information needs. Rudisill (1994) reported from the same study that "what's it doing now", "I wonder why it's doing that", and "well I've never seen that before" are widely heard comments in advanced cockpits, echoing similar concerns by [36].

Many of these problems clearly can be attributed to standard human factors short-comings in interface design. For instance, transitions from one system mode to another may not be salient, designated by small changes in the displayed interface, yet creating very different system behavior. Although the systems are operating properly, operators may be confused as they misinterpret observed system behavior in light of their mental model of a different system mode.

With increased complexity, proving information clearly to operators so that they understand the system state and state transitions becomes much more challenging. Operators may rarely see certain modes or combinations of circumstances that lead to certain kinds of system behavior. Thus, their mental models of the systems may be incomplete. This leaves operators unable to properly interpret observed system actions and predict future system behavior, constituting a significant situation awareness problem.

Although problems with complexity and interface design are somewhat peripheral to automation per se (i.e. these problems also exist in many systems quite apart from any automation considerations), these issues often plague automated systems, and can significantly undermine operator situation awareness in working with automated systems. 


\section{E. Benefits to Situation Awareness}

It should be noted that automation does not always result in these types of problems. Wiener (1985) points out that automation has, for the most part, worked quite well, and has accompanied a dramatic reduction in many types of human errors. Furthermore, he believes that it may improve situation awareness by reducing the display clutter and complexity associated with manual task performance, and through improved integrated displays [37] [38].

It has been suggested that automation may also improve situation awareness by reducing excessive workload. Curry and Ephrath (1977) found that monitors of an automatic system actually performed better than manual controllers in a flight task [39]. As monitors, the authors argued, subjects may have been able to distribute their excess attention to other displays and tasks.

Recent research, however, demonstrates a certain degree of independence between situation awareness and workload [40]. Workload may only negatively impact situation awareness at very high levels of workload. Low situation awareness can also accompany low levels of workload. If workload is reduced through automation, therefore, this may not translate into higher situation awareness.

Furthermore, whether automation actually results in lower workload remains questionable. Wiener's (1985) studies showed that pilots report automation does not reduce their workload, but actually may increase it during critical portions of the flight. Many recent studies are beginning to confirm this. Harris, Goernert, Hancock, and Arthur (1994) and Parasuraman, Mouloua, and Molloy (1994) showed that operator initiation of automation under high workload may increase workload even more [41]. Riley (1994) augments this with his finding that a subject's choice to use automation for a task is not related to the workload level of the task. Grubb et. al. (1994) showed that workload actually was fairly high in tasks where humans must act as monitors over a period of time, as they do with automated systems [42]. Automation in many ways may serve to increase workload, particularly when workload is already high. Bainbridge (1983) called it the irony of automation that when workload is highest automation is of the least assistance [43]. Despite this, however, workload remains the fundamental human factors consideration in many automation decisions.

\section{CONCLUSION}

Considering the information on automation, the impact of automation to situation awareness and the corresponding human performance, it is clear that these issues require further research. Ship designers and operators will continue to be confronted with innovations and advancing technology that may or may not make maritime vessel operation easier and safer. Being able to identify what types of automation are most useful and having the ability to design workable level of automation functions are important skills that designers must possess when looking towards the future.

\section{REFERENCES}

[1] S. B. Lee and I. Kim. "A ship automatic navigation in dynamic environment using artificial intelligence," Proc. of the Fourth International Conference on Knowledge-Based Intelligent Engineering Systems and Allied Technologies, vol.1, pp. 418-422, 2000.

[2] Wickens, C.D. (1992). Engineering Paychology and Human Performance (2nd ed.). New York: Harper Collins.

[3] Wiener, E.L. (1985). Cockpit automation: In need of a philosophy. In Proceedings of the 1985 Behavioral Engineering Conference (pp. 369-375). Warrendale, PA: Society of Automotive Engineers.

[4] Lee, J. D., \& T. F. Sanquist (1996). Maritime automation. In R. Paraduramen \& M. Mouloua (Eds.), Automation and human performance: Theory and applications (pp. 365-384). Mahwah, NJ: Lawrence Erlbaum Associates, Inc.

[5] W. J. Reece, \& H. S. Blackman (1998). Cross-Industry Performance Modeling: Toward Cooperative Analysis. Paper presented at Human Factors and Ergonomics Society Annual Meeting, Chicago.

[6] Hartel, C.E., Smith, K., \& Prince, C. (1991, April). Defining aircrew coordination: Searching mishaps for meaning. Paper presented at the Sixth International Symposium on Aviation Psychology, Columbus, $\mathrm{OH}$.

[7] Endsley, M. R. (1994a, March). A taxonomy of situation awareness errors. Paper presented at the Western European Association of Aviation Psychology 21st Conference, Dublin, Ireland.

[8] Endsley, M. R. (1996). Situation awareness measurement in test and evaluation. In T. G. C. O’Brien, Samuel G. (Ed.), Handbook of human factors testing and evaluation. (pp. 159-180). Hillsdale, NJ, US: Lawrence Erlbaum Associates.

[9] Wagenaar, W. A., \& Groeneweg, J. (1987). Accidents at sea: Multiple causes and impossible consequences. International Journal of ManManchine Studies, 27, 587-598.

[10] Grech, M., \& Horberry, T. (2002,17-18 June 2002). Human error in maritime operation: Situation awareness and accident reports. Paper presented at the 5th Internatinoal Workshop on Human Error, Safety and Systems Development, Newcastle, Australia.

[11] Baker, C. C. Analysis of Coast Guard Marine Safety Management System (MSMS) Data. Technical Report. Houston, Texas: The American Bureau of Shipping, 2002a.

[12] Endsley, M. R. (1988a). Design and evaluation for situation awareness enhancement. In Proceedings of the Human Factors Society 32nd Annual Meeting (pp. 97-101). Santa Monica, CA: Human Factors Society.

[13] Endsley, M. R., \& Kiris, E.O. (1995). The Out-of-the-Loop Performance Preblem and Level of Control in Automation. Human Factors, 37(2), 381-194.

[14] Ephrath, A. R., \& Young, L.R. (1981). Monitoring vs. man-in-theloop detection of aircraft control failures. In J. Rasmussen \&W. B. Rouse (Eds.), Human detection and diagnosis of system failures. New York: Plenum Press.

[15] Kessel, C. J., \&Wickens, C. D. (1982). The transfer of failuredetection skills between monitoring and controlling dynamic systems. Human Factors, 24(1), 49-60.

[16] Wickens, C. D., \& Kessel, C. (1979). The effect of participatory mode and task workload on the detection of dynamic system failures. IEEE Transactions on Systems, Man and Cybernetics, SMC-9(1), 2434.

[17] Young, L. R. A. (1969). On adaptive manual control. Ergonomics, 12(4), 635-657.

[18] Parasuraman, R. (1987). Human-computer monitoring. Human Factors, 29(6), 695-706.

[19] Billings, C. E. (1991). Human-centered aircraft automation: A concept and guidelines (NASA Technical Memorandum 103885). Moffet Field, CA: NASA Ames Research Center.

[20] Danaher, J. W. (1980). Human error in ATC system operations. Human Factors, 22(5), 535-545. 
[21] Parasuraman, R., Molloy, R., \& Singh, I. L. (1993). Performance consequences of automation-induced complacency. International Journal of Aviation Psychology, 3(1), 1-23.

[22] Singh, I. L., Molloy, R., \& Parasuraman, R. (1993). Automationinduced complacency: Development of the complacency-potential rating scale. International Journal of Aviation Psychology, 3(2), 111122.

[23] Lee, J., \& Moray, N. (1992). Trust, control strategies and allocation of function in human-machine systems. Ergonomics, 35(10), 12431270.

[24] Riley, V. (1994). A theory of operator reliance on automation. In M. Mouloua \& R. Parasuraman (Eds.), Human performance in automated systems: Current research and trends (pp. 8-14). Hillsdale, NJ: LEA.

[25] Parasuraman, R., Mouloua, M., \& Molloy, R. (1994). Monitoring automation failures in human-machine systems. In M. Mouloua \& R. Parasuraman (Eds.), Human performance in automated systems: Current research and trends (pp. 45-49). Hillsdale, NJ: LEA.

[26] Parasuraman, R. (1993). Effects of Adaptive Function Allocation on Human Performance. In D. J. Garland \& J. A. Wise (Eds.), Human factors and advanced aviation technologies (pp. 147-158). Daytona Beach, FL: Embry-Riddle Aeronautical University Press.

[27] Wiener, E. L., \& Curry, R. E. (1980). Flight deck automation: Promises and problems. Ergonomics, 23(10), 995-1011.

[28] Cowan, N. (1988). Evolving conceptions of memory storage, selective attention, and their mutual constraints within the human information processing system. Psychological Bulletin, 104(2), 163191.

[29] Slamecka, N. J., \& Graf, P. (1978). The generation effect: Delineation of a phenomenon. Journal of Experimental Psychology: Human Learning and Memory, 4(6), 592-604.

[30] Norman, D. A. (1989). The problem of automation: Inappropriate feedback and interaction not overautomation (ICS Report 8904). La Jolla, CA: Institute for Cognitive Science, U. C. San Diego.

[31] Kuipers, A., Kappers, A., van Holten, C. R., van Bergen, J. H. W., \& Oosterveld, W. J. (1989). Spatial disorientation incidents in the R.N.L.A.F. F16 and F5 aircraft and suggestions for prevention. In Situational Awareness in Aerospace Operations (AGARD-CP-478) (pp. OV/E/1 - OV/E/16). Neuilly Sur Seine, France: NATO AGARD.

[32] Kantowitz, B. H., \& Sorkin, R. D. (1983). Human factors: Understanding people-system relationships. New York: John Wiley \& Sons.
[33] National Transportation Safety Board (1988). Aircraft accident report: Northwest Airlines, Inc., McDonnell-Douglas DC-9-82, N312RC, Detroit Metropolitan Wayne County Airport, August, 16, 1987 (NTSB/AAR-99-05). Washington, D. C.: Author.

[34] Wiener, E. L. (1989). Human factors of advanced technology ("glass cockpit”) transport aircraft (NASA Contractor Report No. 177528). Moffett Field, CA: NASA-Ames Research Center.

[35] McClumpha, A., \& James, M. (1994). Understanding automated aircraft. In M. Mouloua \& R. Parasuraman (Eds.), Human performance in automated systems: Current research and trends (pp. 183-190). Hillsdale, NJ: LEA.

[36] Rudisill, M. (1994). Flight crew experience with automation technologies on commercial transport flight decks. In M. Mouloua \& R. Parasuraman (Eds.), Human performance in automated systems: Current research and trends (pp. 203-211). Hillsdale, NJ: LEA.

[37] Wiener, E. L. (1992, June). The impact of automation on aviation human factors . Paper presented at the NASA/FAA Workshop on Artificial Intelligence and Human Factors in Air Traffic Control and Aviation Maintenance, Daytona Beach, FL.

[38] Wiener, E. L. (1993). Life in the second decade of the glass cockpit. In R. S. Jensen \& D. Neumeister (Eds.), Proceedings of the Seventh International Symposium on Aviation Psychology (pp. 1-11). Columbus, OH: Department of Aviation, The Ohio State University.

[39] Curry, R. E., \& Ephrath, A. R. (1977). Monitoring and control of unreliable systems. In T. B. Sheridan \& G. Johannsen (Eds.), Monitoring behavior and supervisory control (pp. 193-203). New York: Plenum Press.

[40] Endsley, M. R. (1990a). Predictive utility of an objective measure of situation awareness. In Proceedings of the Human Factors Society 34th Annual Meeting (pp. 41-45). Santa Monica, CA: Human Factors Society.

[41] Harris, W. C., Goernert, P. N., Hancock, P. A., \& Arthur, E. (1994). The comparative effectiveness of adaptive automation and operator initiated automation during anticipated and unanticipated taskload increases. In M. Mouloua \& R. Parasuraman (Eds.), Human performance in automated systems: Current research and trends (pp.40-44). Hillsdale, NJ: LEA.

[42] Grubb, P. L., Miller, L. C., Nelson, W. T., Warm, J. S., \& Dember, W. N. (1994). Cognitive failure and perceived workload in vigilance performance. In M. Mouloua \& R. Parasuraman (Eds.), Human performance in automated systems: Current research and trends (pp. 115-121). Hillsdale, NJ: LEA.

[43] Bainbridge, L. (1983). Ironies of automation. Automatica, 19, 775-77 